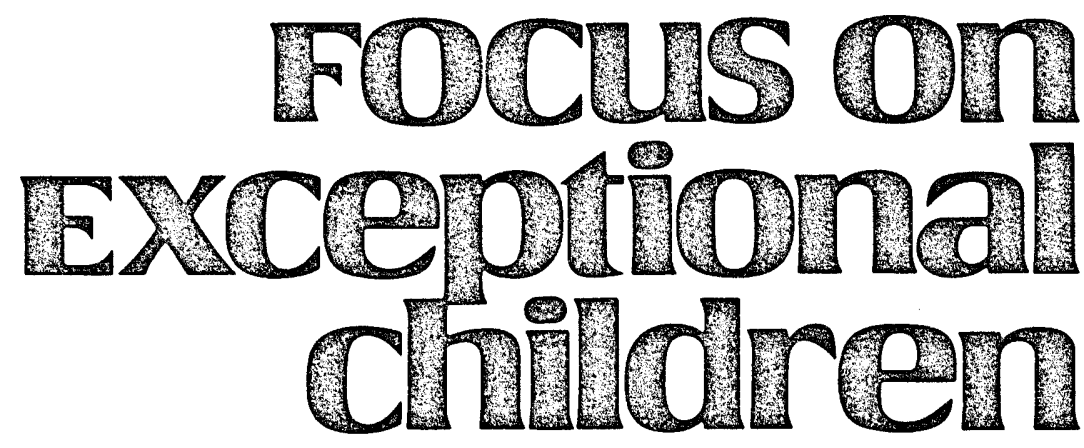

\title{
The Role of Social Interaction In the Development of Thinking Skills
}

\author{
Adriana L. Schuler and Linda Perez
}

The last two decades undoubtedly will go into history as the heyday of teaching technology. Through task analysis, special educators and educators at large have become increasingly capable of devising ingenious lesson plans, reducing complex tasks to carefully sequenced series of operationally defined subskills. This focus on observable behavior has lent itself to remarkably precise measurement, and thereby program fine-tuning through ongoing evaluation of teaching efforts, assuring high rates of correct responding and, ultimately, task mastery. The premise of this evolving technology has been precise operational description and measurement of small segments of observable behavior-a premise that may prove to be its ultimate limitation.

Within the context of a nationwide growing dissatisfaction with the quality of education, dissatisfaction with the long-term outcome of special education efforts has been increasingly voiced. Concerns tend to revolve around limited generalization, lack of functional use of skills taught in school, and limited problem-solving skills. Frustration often is expressed as to whether many of these students will ever learn to think independently.

Teaching special education students introduces extra challenges. Limitations in teaching outcome are not necessarily a reflection of poor teaching, because many special education students are handicapped by sensory and physical conditions that may seriously thwart their cognitive development. Moreover, the bulk of invisible handicaps, such as learning handicaps, perceptual handicaps, behavior disorders, emotional disturbances, and so on, are viewed increasingly as cognitive handicaps revolving around poor planning, organization, self-checking, and problem-solving skills. These limitations in self-regulatory behaviors often are associated with limitations in social-cognitive knowledge, as evidenced by a lack of understanding of others' perspectives and of cause/effect relationships that pertain to their own as well as other people's behavior.

Dr. Schuler is Professor of Special Education, San Francisco State University, where Linda Perez is a Doctoral Candidate.

- Love Publishing Company, 1987. 
This article examines current views on cognitive development and learning pertinent to the needs of special education students. Emphasis is given to the role of language in the form of "self-talk" in planning, behavior organization, and problem solving, and on the importance of social interaction. To put it differently, the self-regulatory functions of language are examined, highlighting the intricate interrelations between language and thinking.

To further clarify this relationship, the discussion of selfregulatory skills is preceded by a brief overview of the interactions of early communicative and cognitive development. In this context the notion of mediation is introduced and then elaborated upon in later sections.

Second, a closely related matter-the role of social interaction in developing thinking skills-is discussed. Because social interaction is viewed as a critical mediating force in communicative development and development in general, its impact on the development of self-regulation

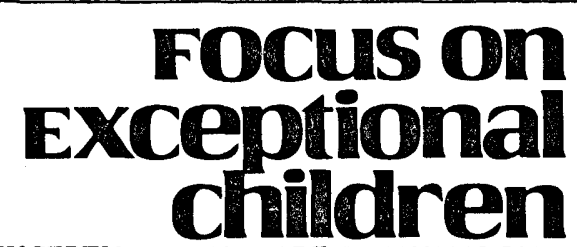

FOCUS ON EXCEPTIONAL CHILDREN (ISSNO015-51IX) (USPS 203-360) is published monthly except June, July, and August as a service to teachers, special educators, curriculum specialists, administrators, and those concerned with the special education of exceptional children. This journal is abstracted and indexed in Exceptional Child Education Resources, and is also available in microform from Xerox University Microfilm, Ann Arbor, Michigan. Subscription rates: Individuals, $\$ 24$ per year; institutions, $\$ 30$ per year. Copyright 01987 , Love Publishing Company. All rights reserved. Reproduction in whole or part without written permission is prohibited. Printed in the United States of America. Second class postage is paid at Denver, Colorado.

POSTMASTER: Send address changes to:

Love Publishing Company

Executive and Editorial Office

1777 South Bellaire Street

Denver, Colorado 80222

Telephone (303) 757-2579

EDITORIAL BOARD

Edward L. Meyen

University of Kansas

Glenn A. Vergason Georgia State University

Richard J. Whelan

University of Kansas Medical Center

Stanley F. Love Publisher
Carolyn Acheson Senior Editor and thinking skills in general deserves close attention. Despite the fact that social interaction has been the major mode through which our species has transmitted culture to its younger members, social interaction has not been viewed as a critical force in prevalent views of learning and development. Major theorists who have impacted educational practices in this country, such as Piaget and Chomsky, typically have expressed little interest in social interaction as a developmental force. This neglect, interestingly, has been paralleled by a similar neglect within behavioral circles. For instance, operant learning principles such as those articulated by Skinner only touch upon other people, as dispensers of reinforcement rather than having interactional qualities.

\section{DEFINITION OF TERMS}

Any discussion of thinking and cognition runs risks of becoming entangled in terminological confusion as well as unresolved controversies such as those pertaining to the effects of language on cognition, and its reciprocal, the effects of cognition on language. The term communication is used here in reference to behavior of one individual that serves to effect behavior of others, involving verbal as well as nonverbal behaviors of varying levels of intentionality and abstraction. The term language is used in reference to a highly formalized system of communication characterized by communicative intent, symbolic reference, and grammatical organization, thereby allowing for the communication of decontextualized meaning.

The term cognition is used in reference to unobservable mental processes applied to stimulus input, providing for interpretation and categorization, and for the creation of mental representations rather than sensory images guiding intentional action. The term social cognition refers to the understanding of own and others' feelings, agendas, and perspectives, and of the causality of human behavior at large.

\section{EARLY COMMUNICATIVE AND COGNITIVE DEVELOPMENT}

Developmentally, communication and cognition both are linked critically to the establishment of intentionality. Both involve the anticipation of behavior sequences on the basis of previously established behavior outcome or inferences about observed contiguity of events. Early communication and cognition both involve the active prediction of subsequent behavior(s) and event(s). The mere act of predicting 
a next occurrence introduces a mental activity over a physical reality, even when only highly routinized and predictable events are involved. In fact, the latter provide the basis for intentional communication, as the violation of anticipated occurrences provides the motivation to act in such a fashion that the anticipated sequence of events is restored. For instance, an infant may learn to extend his or her arms to make an adult continue an interrupted tickling motion.

The desire to communicate thus is rooted within cognitions about event sequences, activated by the desire to confirm hypothesized sequences of events and to take corrective action when hypothesized scripts are violated, allowing for a sense of control. In this view, both early communicative and cognitive development arise from the desire to detect and maintain contingencies. In more cognitive terms, the need to postulate and test rules regarding the relationships between people, objects, and events provides the core of communicative development. What is emphasized here is the active nature of the learning involved, as currently emphasized by researchers in infant development (for a discussion of this issue, see Lewis, 1985), and as opposed to common assumptions underlying special education practices (e.g., De Ruiter \& Wansart, 1983).

Differentiations can be made between thinking that involves people and thinking that involves objects. While predictions about action sequences (i.e., causality) in the physical world may be made void from social interaction, inferences about the social world, involving the cause/effect relationships of own and others' actions, depend highly on apparent consistencies in social interaction. In fact, social cognition is deeply entrenched in interpersonal communication as similar skills are involved (e.g., understanding others' perspectives). In contrast, as discussed in Hoffman (1981), object cognition is not so dependent upon consistencies in social interaction as upon consistencies observed in the rules and regularities within the physical world.

Nevertheless, caregivers may yet arrange for the discovery of these consistencies by arranging an infant's physical environment-thereby imposing a structure that is salient to the infant involved. For instance, in response to an infant's initial attempts to do so, an adult may provide an infant with a number of opportunities to remove lids from receptacles, starting with the easiest ones first. Adults are able to do so on the basis of a keen appraisal of that infant's current interest and agenda, guided by close observation of that infant's behavior, as well as emotional state.

Behaviors of co-interactants are most pertinent to an infant's emerging social and communicative knowledge, as they are the very scope of the infant's investigations of social cause/effect relations. Erratic behavior that is out of line with an infant's focus of attention and action is not conducive to the infant's security and sense of efficacy and ultimately may lead to a sense of powerlessness in the infant. Of interest here is that developmental growth is not viewed as the final outcome of accumulated experience and stimulation but, rather, as the active product of the child's mental processes. Motivation thus is viewed as more than a matter of external reinforcement. The desire to predict, be correct, or, rather, to impose order may be as powerful as the desire to be fed, held, and physically comforted.

As acknowledged in an increasingly growing body of literature pertaining to the role of social interaction in early development, closely attuned and contingent actions of others are a mediating force in early communicative (Snow, 1984) as well as overall cognitive development (Lewis, 1985). Snow (in Snow \& Ferguson, 1977) used the term semantic contingency in descriptions of parents' reference to and interpretation of their children's early actions such as reaching, laughing, smiling, and vocalizing. Similarly, infants' subsequent object manipulations become the topic of caregivers' verbalizations when they become capable of manipulating objects in a more sustained manner. Apparently, caregivers' utterances shift gears, making accommodations for that child's current focus of interest (Snow, 1986). These caregiver behaviors apparently are guided by that caregiver's appraisal of the child's perspectives and interests and by the desire to see the child demonstrate competence.

What is critical here is for the child to learn that what he or she does matters. Contingent responses, such as topic acknowledgment and elaboration, imitation, and the provision of consequences, which teach the child that his or her actions will work to produce desired effects, are at the core of children's early communicative development. Similarly, Watson (1966) has claimed that adult responses that are contingent upon some prior infant behavior facilitate early cognitive development.

The subsequent need for mediation in learning new skills and acquiring new concepts at later points in development is not easily evaluated. Nevertheless, lack of mediation has been reported as a major cause of cognitive breakdown in mildly retarded adolescents (Feuerstein et al., 1981). Furthermore, theorists such as Smith (1983) and Rogoff (1985) have pointed toward the important role of social interaction in the development of literacy. According to Smith, students need "active encouragement to predict, understand, to enjoy" (Smith, 1982, p. 83). 
Gains in reading result from collaborative interactions with adults who do not penalize students for reading failure but who instead provide for success by structuring the learning environment in accordance with the student's needs. As further argued by Smith $(1982,1983)$, typically used remedial reading programs tend to transfer control from the teacher to sources outside the classroom. Hence, they fail to provide for mediation because the predetermined curriculum cannot anticipate what a particular child might be interested in at any given point.

\section{THE INTERPLAY BETWEEN LANGUAGE AND COMMUNICATION}

With early communication and cognition both stemming from the desire to make predictions about observed events, their lifetime interdependence is not surprising, nor is the close interrelation of both with language. Language grows out of nonverbal communication when more diversified communicative functions, demand communication beyond the physical restraints of the "here and now" along with advances in abstraction skills. As discussed earlier, a formalized language system allows for the communication of ideas, needs, feelings, and so on, without reliance on situational context. For a more detailed discussion of the emergence of language as an integral part of more generalized symbolic capabilities, see Bates (1979) and Wolff and Gardner (1982).

Paradoxically, the early prediction of action sequences in highly predictable, routinized contexts sets the stage for the emergence of more abstract reference and grammar, allowing for the gradual decontextualization of meaning. Though the combined forces of established communicative and cognitive advances provide the roots of linguistic development, the subsequent reciprocal impact of language on cognitive and communicative functioning can hardly be underestimated. Communication and cognition mutually impact on each other. When examining the intricate interrelations between social interaction, communication, language, and cognition, the social functions of language have to be differentiated from the more cognitive functions. Although language and thinking are intricately interwoven in a nonlinear fashion, discussion of the interdependence of language and cognition is fruitless if no distinctions are made in the range of functions that language may serve. For instance, a language function such as initiating interactions with currently present individuals does not require a notion of object permanence, while a request for invisible objects does.
One major function of language-self-regulation-is of utmost relevance to cognition. This close interplay between language and cognition is the focus of the remainder of this article.

Although the importance of language for purposes of behavior organization and self-regulation has long been recognized by psychologists (e.g., Vygotsky, 1976), this function has only recently received attention in the United States. This recent interest reflects growing dissatisfaction with a mostly structural perspective on the study of languagewhich has led to the adoption of a more functional perspective, emphasizing the use of language for a range of social as well as cognitive purposes. This is as evident in the proliferation of studies dealing with the pragmatics of language (its use in social context).

Second, a greater interest has been displayed recently in nonobservable dimensions of behavior that are not easily captured in precise operational definitions. Third, at a more applied level and as pointed out earlier, long-term results of the implementation of precise instructional technology, characterized by minute task breakdown, have left many disappointed.

\section{THE DEVELOPMENT OF SELF-REGULATORY AND METACOGNITIVE SKILLS}

Increased interest in self-regulatory processes has been voiced from a number of perspectives. Researchers within the domain of developmental cognitive psychology have investigated so-called metacognitive processes, defined as "thinking about thinking." Major researchers such as Brown (1978) and Flavell (1976) have investigated the when, how, and why of normal children learning to reflect on and direct their own thinking. These metacognitive processes are related to self-regulatory behaviors, as each one involves the deliberate use of reflective strategies. In part, self-regulatory skills emerge out of social interactions and require an awareness of social conventions.

According to Luria $(1960,1961)$, not until ages 4 and 5 do language and cognition play a major role in self-regulatory functions. The beginning of self-regulation involves the internalization of overt caregiver requests, as manifested in the infant's compliance with commands such as "no." Not until children internalize previous overtly repeated adult instructions does covert self-talk play a critical role in self-regulation. At this time self-regulation is intertwined with metacognition at large. For a more extensive discussion of 
these intertwined developments, see Addison-Stone and Wertsch (1984) and Wertsch (1985).

The basic thinking skills of metacognition have been defined as including the prediction and subsequent checking of results of an action or event, the monitoring of ongoing activity, reality testing, and other controlling and coordinating behaviors (Bondy, 1984). To put it in more educational terms, metacognition is a matter of "one's awareness and one's systematic use of efficient learning strategies" (Wiens, 1983), which can be further divided into two basic categories-those dealing with (a) what an individual knows about his or her cognitive abilities, and (b) the ability to control these processes by planning, choosing, and monitoring. Within the domain of information processing theory and artificial intelligence, the term executive function has been applied to top-level management of more basic processes such as memory and attention, introducing a construct predicated upon metacognitive knowledge.

In terms of special education practices, interest in metacognition has been further raised through the investigation of information processing abilities of students commonly labeled as learning disabled. It has been reported that many of these students are not lacking so much in memory or attention span (basic information-processing capabilities) as in the strategic, goal-directed use of these abilities (Hallahan et al., 1983). Learning disabled students thus are viewed increasingly as having deficits in metacognition rather than in attention, perception, and memory, and have become referred to as passive learners, lacking in the effective use of active problem-solving strategies (Torgeson, 1982). Similarly, students labeled as behavior disordered or emotionally disturbed may be viewed as limited in the regulation of their own emotional state as well as in reflection upon the relationships between their own behavior and external events and the perspectives of others.

Therefore, it has been argued that traditional treatment approaches such as stimulus reduction, medication, and behavior modification may be counterproductive, as they all treat the child as a passive organism- "someone you do something to" (Kneedler \& Hallahan, 1981). The old techniques of shielding, manipulating, or medicating the child have merely reinforced the passivity that is at the root of the learning disabled students' problems (Hallahan et al., 1983).

\section{COGNITIVE BEHAVIOR MODIFICATION}

The practice of cognitive behavior modification (CBM) has been suggested as an antidote for problems commonly exhibited by learning disabled students, such as impulsivity, distractibility, and haphazard responding (Meichenbaum, 1980). One of the goals of cognitive behavior modification is to encourage the student to assume an internal locus of control and take responsibility for his or her own learning. This is to be accomplished by equipping the student with effective problem-solving and self-monitoring strategies through application of principles of direct instruction.

As pointed out by Lloyd (1980), cognitive behavior modification practices all share some common features. First, the student is actively involved in the learning process and may increasingly become his or her own teacher, therapist, or trainer. Second, overt or covert forms of verbalization often are part of the teaching procedure, so that behavior may increasingly become regulated by some form of "selftalk," which relates to the third feature-extensive use of modeling. Initially, overt teacher verbalizations are gradually substituted by covert student verbalizations that serve to regulate the behaviors of the student involved, analogous to common assumptions about the development of covert self-talk, as discussed earlier. Fourth, the identification of a series of steps through which students are to proceed to solve a range of problems is often a core ingredient of this type of training. Fifth, many CBM techniques have focused on teaching students to delay their responses in an uncertain situation until alternatives have been considered.

Self-monitoring techniques, such as those described by Kneedler and Hallahan (1981), provide a relatively straightforward example of congitive behavior modification. Here, students learn to monitor their own on-task behavior. After initially being asked to record their on- or off-task behavior in response to some arbitrary external cue (e.g., a beep), students eventually are to be weaned from this external structure and to monitor themselves through more covert self-checking processes. These types of procedures reportedly have resulted in considerably increased on-task behavior, but the results have not been as impressive when academic productivity is applied as a criterion for evaluation.

Other examples include self-instructional training, as described by Meichenbaum and Goodman (1971), in which students are taught to direct their own behavior through self-interrogation, involving phrases such as "remember to go slow," "back up again," "that's okay," and so on. Despite the fact that these types of teaching procedures typically produce gains in the specific training contexts used, maintenance and transfer have been limited. Classroom applicability may be limited as well because of the focus on behavior 
rather than on skill acquisition or learning in more general terms (Torgeson, 1982). Although students may be taught successfully to stop themselves and think, they also need to learn what they should be thinking.

\section{COGNITIVE TRAINING}

In response to the apparent limitations of cognitive behavior modification in the classroom, more specific cognitive strategies have been promoted for precisely attacking specific academic problems. Examples of cognitive training have been reported by Cullinan, Lloyd, and Epstein (1980) in the context of teaching basic multiplication facts (a straightforward example of basic arithmetic computations) and by Atwell and Rhodes (1984) in the less tangible context of reading comprehension. An effective combination of cognitive behavior modification and specific attack strategy training was provided by Brown and Alford (1984) in an effort not only to increase time on-task but also to use specific strategies to analyze a problem. Again, encouraging results were reported in the context of related tasks but limited generalization across tasks.

Apparently, transfer to other tasks may be obtained as long as similar stimulus and response properties are involved but not if tasks employ different materials and responses (McKinney \& Haskins, 1980). Portable coping strategies adapted to a range of problems encountered in school and other domains of life evidently are not that easily taught. Of course, goals as ambitious as generalized coping and problem solving, which normally take a lifetime, may not be taught in one series of training sessions.

The other question that obviously is of relevance here is whether critical periods should be postulated in the development of self-regulation and metacognition. Furthermore, cognitive behavior modification and specific strategy training, which exemplify application of the principles of direct instruction, may not go far enough. As Torgeson (1982) stated, cognitive training will fail unless it can teach not only specific task strategies but also more general academic strategies and, last but not least, reflective skills implying the domains of metacognition and motivation at large.

\section{INSTRUMENTAL ENRICHMENT}

When teaching a broad array of skills, as implied in metacognitive knowledge, the paradigm of direct instruction may not suffice. The unavoidable question that demands closer scrutiny pertains to what type of learning is involved in the acquisition of more generalized, conceptual and abstract knowledge and to what extent nurture rather than nature is involved. Encouraging examples of the positive effects of nurture are provided by alternative cognitive training practices described as instrumental enrichment by Feuerstein (1980) and his co-workers (Feuerstein et al., 1981). Feuerstein's position that intellectual functioning is modifiable is supported by his work with so-called culturally deprived individuals who initially demonstrated mild levels of retardation as measured by traditional IQ tests.

Feuerstein has generated a comprehensive body of work, which includes not only an information processing model of intelligence upon which a program of remediation is based but also an assessment device and an explanation for the individual differences that occur in cognitive development. Instrumental enrichment consists of 15 curriculum packages (called "instruments"), which are paper-and-pencil tests grouped according to presumed areas of cognitive deficit. The packages supply materials for 1-hour lessons, three to five times a week, for a period from 2 to 3 years.

Although these paper-and-pencil exercises, designed to systematically teach thinking skills, provide the centerpiece of instrumental enrichment, the essence of Feuerstein's teaching philosophy is not so much in the paper as in what the classroom teacher can do with it. The materials are merely the tools that a teacher uses to sample and modify students' thinking, with mediated social interaction constituting the process of cognitive change. The interactions in which the teacher engages the students are not of the directive type so typical of common instructional packages, and answers are not simply dichotomized as right versus wrong. Of greatest interest to the teacher is to determine which strategies, if any, students are capable of initiating and to assist these students in developing more effective strategies.

Specific "cognitive deficiencies" may be demonstrated in the way a problem-solving task is approached during one or more phases of the problem-solving process: the input phase (that is, while gathering needed information), the elaboration phase (while operating on the input), or the output phase (dealing with communication of the solution) (Messerer, Hunt, Meyers, \& Lerner, 1984). At the input level, Feuerstein has identified seven specific deficiencies, including problems in labeling, gathering complete information, and systematic searching. At the elaborative level, 10 deficiencies have been identified, such as poor planning, use of irrelevant cues, and comparative thinking. Four types 
of deficiencies have been identified at the output level-e.g., impulsive behavior and egocentric communication.

Many of these problems typify those commonly encountered in learning disabled students. Feuerstein attributes them to a passive attitude, analogous to the view of learning disabled students as passive learners (Torgeson, 1982). According to Feuerstein, this passive attitude is caused by a lack of past mediated learning experiences. Although the learners may have been engaged in many social interactions, systematic instruction about these interactions is lacking, so they remain unmediated. Feuerstein believes that interaction by itself does not guarantee optimal development. What is critical is the deliberate actions of relevant others serving to frame and organize learning experiences for children. Good mediation is viewed as a conglomerate: (a) It is intentional; (b) it is transcendent, moving beyond the here and now in explanations of current events; (c) it assigns meaning to stimuli and interactions; (d) it encourages competence and confidence; and (e) it is concerned with the regulation of behavior, helping the child to gain self-control.

\section{COGNITIVE TRAINING AND THE NOTION OF MEDIATION}

When comparing instrumental enrichment with current cognitive behavior modification practices, the overlap between the two warrants comment. Both capitalize on the need to teach unobservable mental processes in a systematic way, and both are designed to increase self-control and problem-solving ability. The difference lies in the instructional methodology applied. Cognitive behavior modification has adopted principles of direct instruction, whereas instrumental enrichment is more interactive and focuses on student variables pertaining to the specific types of cognitive deficiencies encountered. The latter also is more studentcentered in the sense that is starts with students' current thought processes. It is less judgmental in that interactions between teacher and students are more of a reciprocal than a directive nature, avoiding highly directive and didactic interactions.

In terms of the variables involved in design of instructional programs, instrumental enrichment operates on student variables as well as those that pertain to student responses and context, whereas cognitive behavior modification revolves merely around the breakdown of desirable student responses. Nevertheless, comparisons between various cognitive approaches to teaching should examine the role of task and student variables. Differentiations may have to be made between tasks that are more rather than less conducive to direct instruction and specific strategy training.

For instance, though hypothesis testing and self-checking are extremely critical to fluent reading and comprehension, these types of cognitive, self-regulatory activities should be complemented by more automatic decoding processes. Direct instruction thus may be most conducive to the latter, but mediation-based cognitive training may be more conducive to the former, as it emphasizes student initiation and analysis of the student's current thinking patterns, avoiding regurgitation of externally imposed behaviors.

What makes instrumental enrichment different from enrichment practices as commonly observed within the field of special education is that mere exposure to external stimuli is viewed as insufficient. The adult has to provide the needed structure to allow the child to make sense out of what is experienced, to interpret it, to assimilate it with past experience, and to provide the basis for accurate predictions about future actions and events. The adult arranges for and filters stimulus input in such a way that it provides the child with a basis for detecting contingencies-for the abstraction of rules. As pointed out recently by Gerber (1986), "Good instruction" provides or elicits the amount of structure most likely to maximally reduce response uncertainty, with the amount of structure being provided relating inversely to the cognitive maturity of perspective learners. Provision of the optimum amount of structure is not unique to instrumental enrichment but, rather, is an implicit yet not explicitly specified element of quality teaching.

Feuerstein's view of mediation as a critical mechanism in the transmission of culture and invites comparison with notions of "scaffolding," as introduced by developmental theorists such as Bruner (1975). By carefully structuring young children's events, a scaffold is provided for generating accurate predictions about the outcome of one's own and other people's actions and about the ways in which events are related. The importance of interpersonal exchange, and social interaction in general, as currently stressed in the literature on early communicative development, is remarkably in line with Feuerstein's notion of mediation. Furthermore, the positive effects of caregiver responsiveness and communicative style on language development have been documented in a number of studies (Ainsworth \& Bell, 1974; Cross, 1977; Barnes, Gutfreund, Satterly, \& Wells, 1983; Ellis \& Wells, 1980; Furrow, Nelson, \& Benedict, 1979; Newport, 1977; Mervis, 1984; Peck, 1985).

Although the long-term results of these linguistic and interactive variables are not easily determined, some intrigu- 
ing findings were reported recently by Schlesinger (1986, 1987 , in press). On the basis of her longitudinal study of outcomes relating to early parent-child interaction, she reported that deaf children whose parents had interacted through responsive, mediated dialogue ended up doing significantly better than those exposed to directive monologues. Schlesinger argued that parents who are overwhelmed by the experience of having a child with a disability tend to display a highly directive and restrictive linguistic stance toward controlling their child. Coping parents, on the other hand, use language more frequently with the intent to communicate.

\section{SUMMARY AND IMPLICATIONS}

A number of alternatives and supplements to direct instruction of carefully operationally defined instructional objectives has been proposed. All of them are cognitive in orientation insofar as nonobservable mental processes are the focus. This cognitive orientation appears to come from a growing dissatisfaction with the long-term results of traditional approaches to special education as well as from the growing realization that many of the problems of special needs students are of a cognitive rather than a perceptual nature. More specifically, metacognitive limitations have been implied in many students commonly described as learning disabled, behaviorally disordered, or emotionally disturbed.

Even though cognitive behavior modification is an extension of direct instruction in that the instructional content is expanded to include less observable processes, the other alternatives described offer a further departure from established teaching practices. The training of specific cognitive strategies goes beyond cognitive behavior modification because it focuses on training specific thinking skills rather than overall behavior. Instrumental enrichment, as promoted by Feuerstein, also is cognitive in orientation, but it is different insofar as instruction is more student-centered, less directive and, above all, social interaction-based, congruent with the notion of teachers as mediators of learning.

What remains to be determined is how these various cognitive approaches compare in relation to both student and task variables. For instance, are direct instruction and specific strategy training most useful when tasks require automaticity such as sight word recognition and basic numerical computations? In contrast, are interactive and less externally controlled approaches more conducive to generalized problem solving, inquisitiveness, and positive attitudes about learning and perceptions of self? Also, are these types of approaches more appealing to students who resist highly directive teaching styles? As pointed out by Ellis (1986), highly organized and tightly structured classrooms may inadvertently increase students' dependency on external cues and decrease opportunities for development and use of the metacognitive skills of self-structuring and monitoring.

\section{The Role of Mediation}

The focus on social interaction as a vehicle for problem solving and learning in general concurs with a more widespread interest in the notion of mediation. For instance, social interaction is viewed increasingly as a powerful mediating force in the context of early communicative development, more advanced linguistic development, and cognitive development at large. Rather than being merely a matter of exposure to other people, mediated social interaction is viewed as a matter of active perspective taking-an interpretation that capitalizes on the child's initiations and interests. Through mediated social interaction children are provided with opportunities to postulate and test rules and be successful at affecting their environment.

This is accomplished through the help of keenly observant adults who are attuned to the child's initiations and perspectives. These adults thereby are capable of creating contexts that allow the child to hypothesize correctly and shield that same child from contexts that present insufficient structure and predictability. Thus, the child is provided with opportunities to make correct predictions and successfully affect his or her immediate environment, increasing his or her sense of efficacy and thereby the likelihood of future initiations, hypothesis testing, and problem solving.

Social mediation is viewed as a mechanism designed to mobilize motivational and cognitive forces within the child through the provision of child-centered structure and predictability. If social mediation is viewed as the root of children's evolving sense of control over their surroundings, its consequences pertain to both affective and cognitive domains. Lack of such control thus may be reflected in a lack of initiation, low self-esteem, depression, and overall passivity, analogous to the construct of "learned helplessness," as articulated by Seligman (1975). If caregivers act to enhance a child's sense of predictability and efficacy, that child is protected from a feeling of powerlessness and ultimately of lethargy and depression, which could earily arise when actions and events experienced are perceived as unre- 
lated to one's own actions. Schlesinger's (1987) claim that low socioeconomic status, depression, or parenting of a child with a disability can all through different routes contribute to powerlessness is of interest here.

\section{Nature Versus Nurture}

The notion of mediation invites reevaluation of longstanding controversies regarding the relative contributions of nature versus nurture on development and learning. Although Feuerstein claims that instead of being a fixed entity, intelligence is modifiable through mediation, learning cannot be explained without the postulation of biological correlates; perceived connections between stimuli have to be registered and retrieved at some level of biological organization through some type of learning mechanism. No matter what the environment can supply in terms of responsivity and staging of contexts conducive to motivation and success, actions and their precipitated outcomes have to be associated through some physiological mechanism, determining the ease with which associations are made and how well they are retained over time. These basic physiological processes may have most to do with mental acuity, but so-called executive processes may be more a reflection of nurture-i.e., mediation and experience.

A related question pertains to whether mediation should be viewed as a major developmental force in all cases or as a powerful compensatory mechanism in individuals developmentally at risk. Sameroff and Chandler (1975) have argued for the increased importance of nurture when biological risk factors are involved. They introduced the notion of a "continuum of caretaking casualty," describing the range of deviant outcomes attributed to poor parenting. According to them, the environment has the potential of maximizing or minimizing early developmental complications.

Of particular interest in this discussion is the interaction between development of self-regulation and cognitive development at large. Early neurological status and newborn behavior apparently are poor predictors of developmental outcome past 3 years of age (Drage, Berendes, \& Fisher, 1969; Graham, Ernhart, Thurston, \& Craft, 1962), but social status variables become increasingly important predictors of outcome. As pointed out by Sameroff and Chandler (1975), parenting behavior apparently serves to modulate the effects of perinatal factors.

The question that has to be addressed in accounting for apparent non-linear developmental trends and signs of major behavior reorganization around ages 4 and 5 is the extent to which these changes are a reflection of the emergence of self-regulatory mechanisms. It is just about the age most children demonstrate remarkable gains in self-regulatory abilities. If these types of skills are relatively more susceptible to nurture than earlier acquisitions that are more reflective of relatively constant biological forces, this relative unpredictability indeed could attest to the impact of nurture and explain why socioeconomic status is such a powerful determinant of developmental outcome.

\section{Development of Communicative Behaviors}

The importance of nurturant interactions with adults raises some questions about language use and communicative style in relation to the complexity of child-directed adult talk (see Blank, Rose, \& Berlin, 1978, for a discussion of these complexities) and the functional qualities of that talk. Adult and child discourse should be discussed in terms of its semantic and pragmatic features. As extensively discussed by Wolf Nelson (1985), this emphasizes the need for critical analysis of teacher and parent discourse in terms of which attributes make it most facilitative of communicative and cognitive growth.

A related topic of critical importance pertains to teaching pre- or emerging linguistic students and more generally to the perspectives of cognitive training in the most severely handicapped students, who often are nonverbal. In this context alternative symbol or signal systems, of course, could take the place of speech. Although the use of alternative and augmentative communication systems has been well documented for purposes of requesting and commenting, their use for self-regulatory functions remains largely unexplored. Particularly when dealing with individuals who have pronounced speech and language deficits, self-regulatory functions may well be served through nonverbal means such as pictorial sequences or any other systems or combination of systems incorporating a variety of alternatives to spoken language or even nonverbal precursors of speech. Even though intentional behavioral self-regulation does not emerge until ages 4 to 5 , behavioral precursors of those abilities appear to control behavior at earlier points (see Kopp, 1982, for an extensive discussion of this issue).

Furthermore, self-regulatory functions may appear in children's behavioral repertoires before the emergence of a fully diversified symbol system. For instance, self-regulatory functions of echoing behavior have been reported in the communication of delayed individuals before they established symbolic reference and grammar (Prizant, 1983; 
Schuler \& Prizant, 1985). Also, the increased interest in multiple intelligence (Gardner, 1983) invites the exploration of other than verbal modes of thinking.

Even when self-regulation as such may not be an explicit instructional goal, the notions of mediation and scaffolding are pertinent to even the most severely involved students. By staging a highly motivating context and by capitalizing on the student's initiations and perspectives, effective communicative behaviors involving the use of non-speech modes of communication can be promoted (e.g., see Schuler, 1985).

\section{Role of the Teacher}

Probably the most pertinent issues raised by the social origin of self-regulatory skills and the related notion of mediation have to do with the teacher's role and with teacher-student communication. The prevalence of direct instruction practices and programmed instruction may have created an image of a teacher as a technically skilled designer and dispenser of educational programs. Notions of mediation, however, impose a different image of a teacher. Because adoption of the perspective of individual students and the ability to respond contingently are involved in being an effective mediator, more dynamic interactional qualities are implied.

In fact, social cognitive skills such as affective and cognitive perspective taking (which naturally grow out of social interaction), in conjunction with effective communication skills, may be more critical to effective teaching than is generally assumed. Excellence in teaching may be predicated upon the imposition of the types of skills described by Gardner (1983) as "intra and inter-personal intelligences" upon analytical and inferential skills germane to the provision of task breakdown and sequencing. Gains in learning are the compound results of effective management of task content as well as learner variables (for a further discussion of these critical determinants of learning, see Ross, 1980).

The type of skills that have been attributed to mediation and positive social experiences may be exactly those that provide for effective interactions with students who are limited in these areas and, therefore, could be invaluable to effective teaching. Reappraisal of some of the social-cognitive skills that teachers so easily take for granted seems in order.

\section{REFERENCES}

Addison-Stone, C., \& Wertsch, J. (1984). A social interaction analysis of learning disabilities. Journal of Learning Disabilities, 17, 194-198.

Ainsworth, M.D.S., \& Bell, S.M. (1974). Mother-infant interaction and the development of competence. In K.J. Connolly \& J.S. Bruner (Eds.), The growth of competence. New York: Academic Press.

Atwell, M.A., \& Rhodes, L.K. (1984). Strategy lessons as alternatives to skills lessons in reading. Journal of Reading, 27(8), 700-705.

Barnes, S., Gutfreund, M., Satterly, D., \& Wells, G. (1983). Characteristics of adult speech which predict children's language development. Journal of Child Language, 10, 65-84.

Bates, E. (1979). The emergence of symbols: Cognition and communication in infancy. New York: Academic Press.

Blank, M., Rose, S., \& Berlin, L. (1978). The language of learning. New York: Grune \& Stratton.

Bondy, E. (1984). Thinking about thinking: Encouraging children's use of metacognitive processes. Childhood Education, 6(4), 234-238.

Brown, A.L. (1978). Knowing when, where, and how to remember: A problem of metacognition. In R. Glaser (Ed.), Advances in instructional psychology. Hillsdale, NJ: John Wiley.

Brown, R.T., \& Alford, N. (1984). Ameliorating attentional deficits and concomitant academic deficiencies in learning disabled children through cognitive training. Journal of Learning Disabilities, 17(1), 20-26.

Bruner, J.S. (1975). The ontogenesis of speech acts. Journal of Child Language, 2, 1-20.

Cross, T. (1977). Mothers' speech adjustments: The contributions of selected child listener variables. In C. Snow \& C. Ferguson (Eds.), Talking to children. Cambridge, England: Cambridge University Press.

Cullinan, D., Lloyd, J., \& Epstein, M. (1980). Strategy training: A structured approach to arithmetic instruction. Exceptional Education Quarterly, 2, 41-50.

DeRuiter, J.A., \& Wansart, W.L. (1983). The psychology of learning disabilities. Rockville, MD: Aspen Systems Corp.

Drage, J.S., Berendes, H.W., \& Fisher, P.D. (1969). The Apgar score and four-year psychological examination performance. In Perinatal factors affecting human development. Proceedings, Pan American Health Organization WHO (Scientific Publication No. 185), pp. 222226.

Ellis, S.E. (1986). The role of motivation and pedagogy on the generalization of cognitive strategy training. Journal of Learning Disabilities, 19(2), 66-70.

Ellis, R., \& Wells, G. (1980). Enabling factors in adult-child discourse. First Language, 1, 46-82.

Feuerstein, R. (1980). Instrumental enrichment. Baltimore, MD: University Park Press.

Feuerstein, R., Miller, R., Hoffman, M.B., Rand, Y., Mintzker, Y., \& Jensen, R.J. (1981). Cognitive modifiability in adolescence: Cognitive structure and the effects of intervention. Journal of Special Education, $15,273$.

Flavell, J. (1976). Metacognitive aspects of problem solving. In L. Resnick (Ed.), The nature of intelligence. Hillsdale, NJ: Lawrence Erlbaum Assoc.

Furrow, D., Nelson, K., \& Benedict, H. (1979). Mothers' speech to children and syntactic development: Some simple relationships. Journal of Child Language, 6, 423-442.

Gardner, H. (1983). Frames of mind. New York: Basic Books.

Gerber, M.M. (1986). Cognitive-behavioral training in the curriculum: Time, slow learners, and basic skills. Focus on Exceptional Children, 18(6), 1. 
Graham, F.K., Ernhart, C.B., Thurston, D.L., \& Craft, M. (1962). Development three years after perinatal anoxia and other potentially damaging newborn experiences. Psychological Monographs, 76(3). (Series no. 522).

Hallahan, D., Hall, R.J., Ianna, S., Kneedler, R.D., Lloyd, J., Loper, A.B., \& Reeve, D.J. (1983). Summary of research findings at the University of Virginia Learning Disabilities Research Institute. Exceptional Education Quarterly, 4,95-115.

Hoffman, M.L., (1981). Perspectives on the difference between understanding people and understanding things: The role of affect. In J. H. Flavell \& L. Ross (Eds.), Social cognition. Cambridge, MA: Cambridge University Press.

Kneedler, R.D., \& Hallahan, D.P. (1981). Self-monitoring of on-task behavior with learning disabled children: Current studies and directions. Exceptional Education Quarterly, 2, 73-78.

Kopp, C.B. (1982). Antecedents of self-regulation: A developmental perspective. Developmental Psychology, 18, 199-214.

Lewis, M. (1985). Developmental principles and their implications for at-risk and handicapped infants. In M. Hanson, Atypical infant development. Austin, TX: PRO-ED.

Lloyd, J. (1980). Academic instruction and cognitive behavior modification: The need for attack strategy training. Exceptional Education Quarterly, 4, 53-63.

Luria, A.R. (1960). Verbal regulation of behavior. In M.A.B. Brazier (Ed.), Conference on central nervous system and behavior. New York: Josiah Macy Foundation.

Luria, A.R. (1961). The role of speech in the regulation of normal and abnormal behavior. London: Pergamon Press.

McKinney, J.D., \& Haskins, R. (1980). Cognitive training and the development of problem-solving strategies. Exceptional Education Quarterly, 4, 41-51.

Meichenbaum, D. (1980). A cognitive behavioral perspective on intelligence. Intelligence, 4, 271-283.

Meichenbaum, D., \& Goodman, J. (1971). Training impulsive children to talk to themselves: A means of developing self-control. Journal of Abnormal Psychology, 77, 115-126.

Mervis, C. (1984). Early lexical development: The contributions of mother and child. In C. Sophian (Ed.), Origins of cognitive skills. Hillsdale, NJ: Erlbaum.

Messerer, J., Hunt, E., Meyers, G., \& Lerner, J. (1984). Feuerstein's instrumental enrichment: A new approach for activating intellectual potential in learning disabled youth. Journal of Learning Disabilities, $17(6), 322-325$.

Nelson, W.N. (1985). Teacher talk and child listening-Fostering a better match. In C.S. Simon (Ed.), Communication skills and classroom success. San Diego: College-Hill Press.

Newport, E. (1977). Motherese: The speech of mothers to young children. In N.J. Castellan, D. Pisoni, \& G. Potts (Eds.), Cognitive theory (Vol. 2). Hillsdale, NJ: Erlbaum.

Peck, C.A. (1985). Increasing opportunities for social control by children with autism and severe handicaps: Effects on student behavior and perceived classroom climate. Journal of the Association for Persons with Severe Handicaps, 10(4), 183-193.

Prizant, B. (1983). Language acquisition and communicative behavior in autism. Toward an understanding of the whole of it. Journal of Speech \& Hearing Disorders, 48.

Ross, A. (1980). Learning disability unreal. New York: McGraw Hill.

Rogoff, B. (1985). Adult assistance of children's learning. In T.E. Raphael \& R.E. Reynolds (Eds.), Contexts of literacy. New York: Longman.
Sameroff, A., \& Chandler, M.J. (1975). Reproductive risk and the continuum of caretaking casualty. In F.D. Horowitz (Ed.), Review of child development research (pp. 187-244). Chicago: University of Chicago Press.

Schlesinger, H.S. (1986). Reliance on self and others: Autonomy and the lessening of dependency of young deaf adults. In D.H. Ashmore (Ed.), Proceedings of the Regional Conference on Postsecondary Education for Hearing Impaired Persons. Knoxville, TN: University of Tennessee, Postsecondary Education Consortium.

Schlesinger, H.S. (1987). Effects of powerlessness on dialogue and development: Disability, poverty and the human condition. In B. Heller, L. Flohr, \& L. Zegans (Eds.), Psychosocial interventions with sensorially disabled persons. New York: Grune \& Stratton.

Schlesinger, H.S. (In press). Dialogue in many worlds: Adolescents and adults-hearing and deaf. In G. Anderson (Ed.), Proceedings of the Second Conference on Deaf Adolescents. State University, AR: Research and Training Center.

Schuler, A.L. (1985). Selecting augmentative communication systems on the basis of current communicative means and functions. Australian Journal of Human Communication Disorders, 13(2), 99-116.

Schuler, A.L., \& Prizant, B. (1975). Echolalia. In E. Schopler \& G. Mesibov, (Eds.), Communication problems in autism. New York: Plenum.

Seligman, M.E.P. (1975). Helplessness: On depression, development and death. San Francisco: Freeman.

Smith, F. (1982). Understanding reading, A psycholinguistic analysis of reading and learning to read (3rd ed.). New York: Holt, Rinehart \& Winston.

Smith, F. (1983). Essays into literacy, selected papers and some afterthoughts. Exeter, London: Heinemann.

Snow, C. (1984). Parent-child interaction and the development of communicative ability. In R.L. Schiefelbusch \& D. Pickar (Eds.), The acquisition of communicative competence. Baltimore: University Park Press.

Snow, C. (1986). Conversations with children. In P. Fletcher \& M.. Garman (Eds.), Language acquisition (2nd ed.). New York: Cambridge University Press.

Snow, C., \& Ferguson, C. (1977). Talking to children: Language input and acquisition. Cambridge, England: Cambridge University Press.

Torgeson, J.K. (1982). The learning disabled child as an inactive learner: Educational implications. Topics in Learning Disabilities, 2, 45-52.

Vygotsky, L.S. (1976). Play and its role in the mental development of the child. In J.S. Bruner, A. Jolly, \& K. Sylva, Play: Its role in development and evaluation. New York: Basic Books. (Original work published 1933)

Watson, J. (1966). The development and generalization of contingency awareness in early infancy: Some hypotheses. Merrill-Palmer Quarterly, 12, 123-135.

Wertsch, J.V. (1985). Vygotsky and the social formation of mind. Cambridge, MA: Harvard University Press.

Wiens, J.W. (1983). Metacognition and the adolescent passive learner. Journal of Learning Disabilities, 16, 144-149.

Wolff, R., \& Gardner, H. (1982). Structure of early symbolization. In D. Bricker \& R. Schiefelbusch, Early language. Baltimore: University Park Press.

The authors thank Marci Hanson, Cheri Hamilton, Charles Peck, Barry Prizant, and James Podratz for their input and support in the preparation of this manuscript. 


\section{Professional update}

\section{NEW BOOKS}

\section{Accessibility to Employment Training}

For the Physically Handicapped

by Thomas L. Erekson and Anthony F. Rotatori

This book is a helpful guide for those who are involved with employment training for the physically handicapped. It gives applicable legislation, resource listings of materials, organizations, and equipment suppliers, and other practical tools and suggestions. Major topics covered include the various disabilities constituting this handicapped group, motor and vocational assessment, accessibility considerations, and specific techniques used with each of the disabilities discussed.

The book promotes awareness of the unique needs and provisions of the physically handicapped in a work environment. Instructional personnel and planners will find it useful in programming and delivery of employment training. The publisher of this 160-page hardbound book is Charles C. Thomas, Springfield, IL.

\section{A User's Guide to Community Entry For the Severely Handicapped By Ernest Pancsofar and Robert Blackwell}

Here is a new book that presents guidelines for developing comprehensive residential options for severely handicapped individuals leading to placement in the least restrictive environment. The orientation is toward developing appropriate facilities to meet the needs within the community rather than fitting persons in need of care into predetermined settings. The concept of normalization is discussed first, followed by the range of options, and how to evaluate them, financing, transitions from previous living environments, personnel and staff considerations, instructional strategies, leisure time planinng, and more.

It is surprising how much practical information is packed into these pages. There are checklists, listings of criteria and requirements for various settings, suggestions for volunteers, itemized household tasks, existing program listings, and the like. The State University of New York Press (Albany) is the publisher of this 182-page hardbound book.

\section{Stress in Childhood: \\ An Intervention Model for Teachers And Other Professionals \\ By Gastin E. Blom, Bruce D. Cheney, and James E. Snoddy}

The premise of this book is that teachers are in an excellent position to help children learn how to deal with stress, because of their almost-daily association with them. This book presents a model that teachers and other caregivers can apply without becoming therapists (a role for which they are not prepared).

The discussion covers definitions, sources of stress, children's reactions and how to interpret them, interventions and referrals, health-related stressors, coping strategies, and bibliotherapy. Many personal examples are given to show how the model works. The tone is pragmatic and encouraging. It probably will be of most interest to elementary school administrators, teachers, and associated personnel, as well as special education teachers. Parents also may find it helpful. Published by the Teachers College Press, New York, this paperback is 210 pages in length.

\section{$* * *$}

\section{Emerging Perspectives on Assessment Of Exceptional Children Edited by Randy Elliot Bennett and Charles A. Maher}

A monograph also published as the journal Special Services in the Schools, Vol. 2, Nos. $2 \& 3$, this hardbound version explains special education assessment in terms of emerging conceptual perspectives and practical advances in assessment technology. It discusses both direct and indirect measures of social and effective functioning, as well as learning potential devices. In a nutshell, it covers the successful components of effective assessment for special service providers in the schools.

Some of the chapter topics are curriculum-based measurement, path-referenced assessment, functional psychoeducational assessment, cognitive assessment, neuropsychological assessment, personality assessment, preschool assessment, and minimum competency testing. The many contributors have specialized expertise in each of these areas. This book is available from Haworth Press, New York. 